\title{
ENDEMISM, GIGANTISM AND EXTINCTION IN ISLAND LIZARDS: THE GENUS GALLOTIA ON THE CANARY ISLANDS
}

\author{
Barahona, F. ${ }^{a}$, Evans, S.E. ${ }^{a}$, Mateo, J.A. ${ }^{b}$, García-Márquez, M. ${ }^{b}$, López-Jurado, L.F. ${ }^{c}$
}

\footnotetext{
a Dept. of Anat./Developmental Biology, University College London, Rockefeller Building, University Street, London WC1E 6JJ, United Kingdom

b Asoc. Herpetologica Espanola, C/Patalayegua 2, 38913 Tigaday, El Hierro, Spain

c Departamento de Biología, Universidad de Las Palmas, Apart. 550.35080, Las Palmas de Gran Canaria, Spain
}

\begin{abstract}
In the Canary Islands five extant and two extinct giant lacertid lizards belonging to the endemic genus Gallotia are known. A comparative study of the living and subfossil specimens from the Western Canary Islands demonstrates that the extinct giant species Gallotia goliath and Gallotia maxima are synonymous with the living Gallotia simonyi. Characters formerly used in the diagnosis of the extinct species and subspecies fall within the range of intraspecific variation (ontogenetic and individual) of the living species. The only significant difference between living and subfossil populations of $G$. simonyi is size, and there is strong evidence to suggest that the reduction in size in living populations reflects shorter life expectancy, a factor that should be taken into account in the current conservation projects on this species.
\end{abstract}

